\title{
Evolutionary analysis of rabies virus isolates from Guangxi Province of southern China
}

\author{
Xian-Kai Wei ${ }^{1,2}$, Xiao-Xia He ${ }^{2}$, Yan Pan ${ }^{1,2}$, Cheng Liu², Hai-Bo Tang ${ }^{1,2}$, Yi-Zhi Zhong ${ }^{2}$, Xiao-Ning Li, ${ }^{1,2}$, \\ Jing-Jing Liang ${ }^{1,2}$ and Ting Rong Luo ${ }^{1,2^{*}}$ (D)
}

\begin{abstract}
Background: Rabies is a severe epidemic in Guangxi province, China, with hundreds of deaths occurring each year. In the past six decades, rabies has emerged three times in Guangxi, and the province has reported the largest number of rabies cases in China. The domestic dog is the principal vector for rabies, and 95\% of human cases are associated with transmission from dogs.

Results: To understand the genetic relationship between street rabies virus (RABV) from Guangxi, genetic diversity analysis was performed using RABV isolates collected between 1999 and 2012. The N gene of 42 RABV isolates, and the $P$ and $M$ genes, as well as fragments of the $3^{\prime}$ terminus $\left(L^{1-680}\right)$ and the polymerase activity module of the $L$ gene $\left(L^{\text {pam }}\right)$ of 36 RABV isolates were sequenced. In addition, whole genome sequencing was performed for 5 RABV isolates. There was evidence of topological discrepancy in the phylogenetic trees based on different genes of the RABV isolates. Amino acid variation of the deduced N protein exhibited different patterns to those obtained from the $\mathrm{P}$ and $\mathrm{M}$ proteins reported here, and the previously reported $\mathrm{G}$ protein (Tang H. et al., PLoS Negl Trop Dis, 8(10): e3114, 2014), and $L^{1-680}$ and $L^{\text {pam }}$. These RABV isolates were divided into three main branches against fixed strains.

Conclusion: RABV is prevalent in Guangxi province and strains collected over the last two decades belong mainly to three groups (I, II, III). These RABV isolates reveal genetic diversity. Individual RABV genes from Guangxi exhibit different evolutionary characteristics. The results will have benefits for continuing comprehensive rabies surveillance, prevention and control in China.
\end{abstract}

Keywords: Rabies virus, Genetic diversity, Evolution

\section{Background}

The rabies virus (RABV), a member of the Lyssavirus genus, which is found worldwide, causes lethal viral encephalitis in a wide range of host species. Rabies is of specific concern as it is fatal to humans and has a significant impact on public health.

Previous research on the phylogenetic analysis of the RABV N gene has identified differences in RABVs found in bats, compared to those found in terrestrial mammals $[1,2]$. A better understanding of the $\mathrm{N}$ gene evolutionary trajectory can assist the development of control

\footnotetext{
* Correspondence: tingrongluo@gxu.edu.cn

'State Key Laboratory for Conservation and Utilization of Subtropical Agro-Bioresources, Guangxi University, Nanning 530004, Guangxi, China ${ }^{2}$ Laboratory of Veterinary Microbiology and Animal Infectious Diseases, College of Animal Sciences and Veterinary Medicine, Guangxi University, Nanning 530004, Guangxi, China
}

measures [3, 4]. Evolutionary analysis based on the lyssavirus surface glycoprotein (ectodomain) revealed that point mutations are the most frequent mutation in lyssavirus evolution; additionally, all lyssavirus lineages have similar evolutionary rates [5]. Phylogenetic analyses of $\mathrm{N}, \mathrm{P}$, and $\mathrm{G}$ gene sequences among bat lyssaviruses from central Asia have demonstrated that quantitative overlap between the currently established genotypes likely occurs at the amino acid level $[6,7]$. Phylogenetic analysis based on the full RABV genome, or based on N, P, $\mathrm{M}, \mathrm{G}$, and $\mathrm{L}$ genes, resulted in phylogenetic trees with similar topologies, indicating that individual lyssavirus genes are likely sufficient to establish phylogenetic relationships [8]. This suggests that rigorous phylogenetic techniques based on full-length genome sequences provide considerable discriminatory power for genotype classification within the lyssaviruses [9]. The current global understanding of RABV phylogeography is that there

(c) The Author(s). 2018 Open Access This article is distributed under the terms of the Creative Commons Attribution 4.0 International License (http://creativecommons.org/licenses/by/4.0/), which permits unrestricted use, distribution, and 
are six clades of RABV in non-flying mammals, each with a distinct geographical distribution, likely reflecting major physical barriers to gene flow.

In China, human rabies has re-emerged since 1997. Two distinct clades of RABV isolates found in China were identified by genetic analysis [10, 11]. Investigation of the molecular epidemiology of rabies in southern China has demonstrated that long-distance migration, or trans-provincial movement of dogs (by humans) from high-incidence regions may be one of the causes of the recent human rabies epidemics in southern China [12]. Evolutionary dynamic analysis based on the $\mathrm{G}$ gene shows that the RABV currently circulating in China consists of three main groups [13], and that the RABV in China and Southeast Asia share a common ancestor [14]. Phylogenetic analysis based on the 3 ' terminus of the $\mathrm{N}$ gene shows that RABV isolates from Guangxi province, south China can be divided into four groups [15]. Further studies have demonstrated that isolates from groups I, II, and III are lethal once introduced in mice, whereas isolates of group IV are not fatal to either adult or suckling mice [15].

In this study we sequenced the $\mathrm{N}, \mathrm{P}$ and $\mathrm{M}$ gene as well as $L^{1-680}$ and $L^{\text {pam }}$ of the Guangxi isolates. In addition, we performed whole-genome sequencing for 5 of the isolates. The goal of this study was to identify novel genetic features, in several different RABV genes, that may have occurred in the evolutionary process of Guangxi RABV. Due to the fact that live attenuated rabies vaccines have been used in Guangxi in the past, and these vaccines contain RABV strains with the potential for replication and reversion to the pathogenic form, all field isolates were compared against these vaccine strains.

\section{Methods}

\section{Isolation of virus}

Between 1999 and 2012, 42 RABV isolates were obtained from rabid dogs, cattle, pigs, and asymptomatic dogs that were received from different regions of Guangxi. All samples were provided by the Guangxi Center for Animal Diseases Control and Prevention, with permission from the Veterinary Administration of the Guangxi Provincial Government. Samples were subjected to RT-PCR, and the positive samples were further used for RV isolation by mouse inoculation test [15]. Mice were purchased from the Animal Centre of Guangxi Medical University. To comply with Animal Research as Reporting In Vivo Experiments (ARRIVE) guidelines, all husbandry and experimental procedures were conducted in compliance with the Animal Welfare Act and the Guide for the Care and Use of Laboratory Animals. The mice were euthanized in a container after application of halothane inhalant, with the container closed once the aenesthesized mouse displayed a lack of righting reflex (mouse unable to right itself within $10 \mathrm{~s}$ after being placed on its side). Reference sequences of Lyssaviruses sequences used for constructing the phylogenetic tree were sourced from GenBank (Additional file 1: Table S1).

\section{RNA extraction and reverse transcription}

Total viral RNA was extracted from original host or mouse brain using Trizol (Invitrogen Biotechnology Co., Ltd, California, America). Following the manufacturer's instructions, cDNA was synthesized using $2.5 \mu \mathrm{g}$ total RNA, $1 \mu \mathrm{L}(25 \mathrm{pMol} / \mu \mathrm{L})$ sense primer of each pair, and 100 U MuMLV RTase (Promega Trading Co., Ltd, Wisconsin, America) in a $25 \mu \mathrm{L}$ reaction volume using standard methods. Each viral gene or fragment was amplified by RT-PCR using ExTaq (Takala Biomedical Technology Co., Ltd, Dalian, China) DNA polymerase.

\section{Cloning and sequencing of viral genes}

Primers used for amplification of RABV genes are shown in Additional file 2: Table S2. This table includes gene sequences, nucleotide positions, lengths, and regions.

PCR products were separated on $1 \%$ agarose and stained with ethidium bromide, purified and cloned into the pMD18-T cloning vector, and sequenced by Takara Corp. Three clones were analyzed for each amplicon of each virus. Sequence information was aligned and edited using DNAStar software.

\section{Phylogenetic analysis}

The coding regions of the $\mathrm{N}, \mathrm{P}$, and $\mathrm{M}$ genes and the $\mathrm{L}^{1-}$ ${ }^{680}$ and $\mathrm{L}^{\text {pam }}$ regions of the genome of the isolates from Guangxi (accession numbers in Additional file 3: Table S3) were used to construct a phylogenetic tree. Homologous sequences were aligned using the Clustal method of the MegAlign program of DNAStar version 7.1 (DNAS TAR $_{\text {TA }}$ Inc., USA) [16]. A Maximum likelihood (ML) tree for all DNA sequences was constructed using the Kimura 2-parameter model with MEGA5.0 software [17, 18].

\section{Results \\ Phylogenetic analysis of RABV using the $N, P$, and $M$ genes and regions $L^{1-680}$ and $L^{\text {pam }}$}

A total of $42 \mathrm{RABV}$ isolates were obtained from different locations in Guangxi between 1999 and 2012. The N of 42 RABV isolates, and the $\mathrm{P}$ and $\mathrm{M}$ genes, as well as fragments of the $3^{\prime}$ terminus $\left(\mathrm{L}^{1-680}\right)$ and the polymerase activity module of the $\mathrm{L}$ gene $\left(\mathrm{L}^{\mathrm{pam}}\right)$ of $36 \mathrm{RABV}$ isolates, and the whole genomes of 5 RABV isolates were sequenced (Additional file 3: Table S3). Maximum likelihood phylogenetic trees were constructed for 113 complete $\mathrm{N}$ sequences (including the isolates (from Asia) downloaded from GenBank), 84 complete P sequences, 84 complete $M$ sequences, $83 \mathrm{~L}^{1-680}, 83 \mathrm{~L}^{\text {pam }}$, and 49 whole genome sequences, including a set of laboratory-passaged 
strains and street RABV strains from other locations (Additional file 1: Table S1).

Constructing phylogenetic trees for each of the N, P, and $M$ genes, $\mathrm{L}^{1-680}, \mathrm{~L}^{\mathrm{pam}}$ and the whole genome, revealed different topologies with strong bootstrap values. Isolates from Guangxi could be divided into three groups, designated I, II, and III (Figs. 1, 3, 4, 5, 6 and 7). Group I included isolates from the Guizhou, Hunan, Jiangxi, Fujian and Zhejiang provinces. Group II contained isolates from the Yunnan, Guizhou, Hunan, Anhui, Jiangsu, and Henan provinces. Group III contained isolates from Guangxi and Yunnan, and from the Southeast Asia countries. Of which, the two main groups (I and II) are related to China I (Clade I) and II (Clade II) [19-21], also associated with Asia1 and Asia2 [14]. We compared the $\mathrm{N}$ gene of 113 isolates from the world and constructed the phylogenetic tree, indicating that an India isolate and a Sri Lanka isolate are classified as Asia1, the China I and II are classified as Asia2 and Asia3. Compared with the Asia area, the isolates of group I in Guangxi (GX I) belong to the Asia2, including the isolates from Chinese Hunan, Jiangxi, Zhejiang, Fujian provinces, and including some isolates (94280PHI/dog/1994/ Philippines/EU086202 and 03006PHI/human/2000/ Philippines/EU086203) from the Philippines. The isolates of group II in Guangxi (GX II) belong to the Asia3, including the isolates from Chinese Yunnan, Guizhou, Hunan, Anhui, Jiangsu, Henan provinces and Shanghai. The RABV isolates of GX I and GX II are principally from the epidemic in Guangxi or from some other provinces of China. The isolates of group III in Guangxi (GX III) belong to Asia4. In the past two decades only three isolates were collected from China, GXN119 was isolated from Guangxi in 2000, and N11 was also from Guangxi, Tc06 from Yunnan; the other isolates were reported in the Southeast Asia countries Thailand, Vietnam, Myanmar, Cambodian and Laos, and were classified as Asia4 [15], indicating that GXIII (Asia4) is mainly prevalent in the Southeast Asia countries (Fig. 2), and the group III is associated with SEA3, as designated in a previous study [21].

Furthermore, the relationship between the three branches varied depending on the gene segment employed. The tree generated from the full $\mathrm{N}$ gene, the previously reported $G$ gene [22] and $L^{\text {pam }}$ had a branching pattern where groups II and I were linked while group III formed a separate branch. For trees generated from the $\mathrm{P}$ gene, groups I and II were clustered most closely while group III formed a separate, outlying branch. However, for the $\mathrm{M}, \mathrm{L}^{1-680}$ and whole genome trees, groups I and III were most closely related, while group II formed a separate, outlying branch (Figs. 1, 3, 4, 5, 6 and 7 and Table 1).

\section{Amino acid variation in RABV isolates}

Totally, the nucleotide sequence data from RABV isolates showed that $\mathrm{N}, \mathrm{M}$ genes and two fragments $\mathrm{L}^{1-680}$ and $\mathrm{L}^{\mathrm{pam}}$ were highly conserved, with the exception that a few nucleotides of the $\mathrm{P}$ gene varied. On comparison of deduced amino acid (aa) sequences from N, P, M genes, the fragments of $\mathrm{L}^{1-680}$ and $\mathrm{L}^{\mathrm{pam}}$, as well as the whole genome of 5 isolates, we found that most of the functional motifs mapped in the different genes of RABV isolates were extremely conserved. Details are described as follows.

\section{$N$ amino acid variations}

Based on the deduced amino acid sequences, the specific epitope (358-367aa) of B cells, the principal epitope (404-418aa) of Th and RNA binding site (298-352aa) were highly conserved [23]. A phosphorylation site S389, related to viral transcription and replication, was also highly conserved [24]. Comparison of the entire N protein of all isolates with that of the ERA, commonly used as a reference strain, showed two specific amino acid substitutions at positions 90 and 110 of group I: T90 N and E110D. In group II, the threonine in ERA was replaced by serine (T42S). The single isolate in group III, GXN119, and isolate 8743THA from Thailand showed 3 different substitutions (L128 V, P135A, and T375 M). In addition, all isolates from Guangxi and other provinces of China had variations at 5 locations that were conserved across regions I, II and III: H26Y, C40S, S61 N, V95 L, and G106D (Additional file 4: Table S4).

\section{$P$ amino acid variations}

For the P protein, several functional domains - L protein binding region [25] (1-19aa), LC8 binding motif [26] (144-148aa) and $\mathrm{N}$ protein binding region [27] (209-216aa) - were highly conserved. Nuclear export signal [28] (49-58aa) had two variations: G54R/H57Q in the three groups and one variation E51D in group II. Th/Tc epitope (191-206aa) had one variation, K192E, in the three groups. It is unclear whether the functions of these domains have been influenced or not by these mutations. A phosphorylation site serine at 63aa that was changed to proline (S63P) removed the phosphorylation function.

There were three specific substitutions (A70T, A130M and V131 T) in group I, five specific substitutions (P134S, N135 T, S140P, R151K and A174V) in group II, and six specific substitutions (G73 V, S162 L, Q167K, K239R, D253E, and D281E) in group III. At residue 130, the A130M substitution was specific to group I, while the A130T substitution was specific to group II. At residue 174, the A174V substitution was specific to group II, while the A174E substitution was specific to group III. Four substitutions (H57Q, S63P, S90G, and A241S) were common to all isolates from Guangxi (Additional file 5: Table S5). 


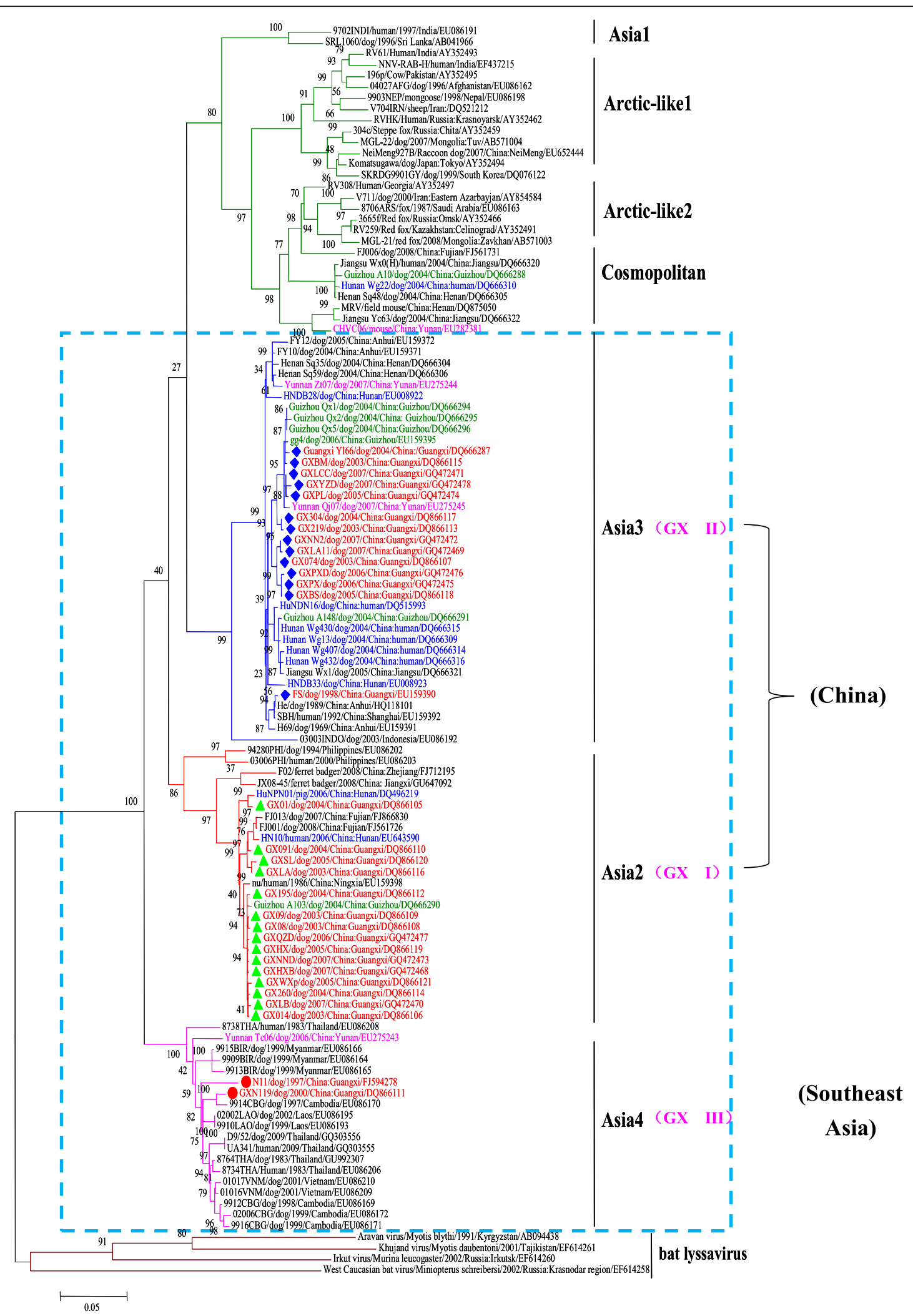

Fig. 1 Phylogenetic tree based on nucleotide sequences of $\mathrm{N}$ gene 


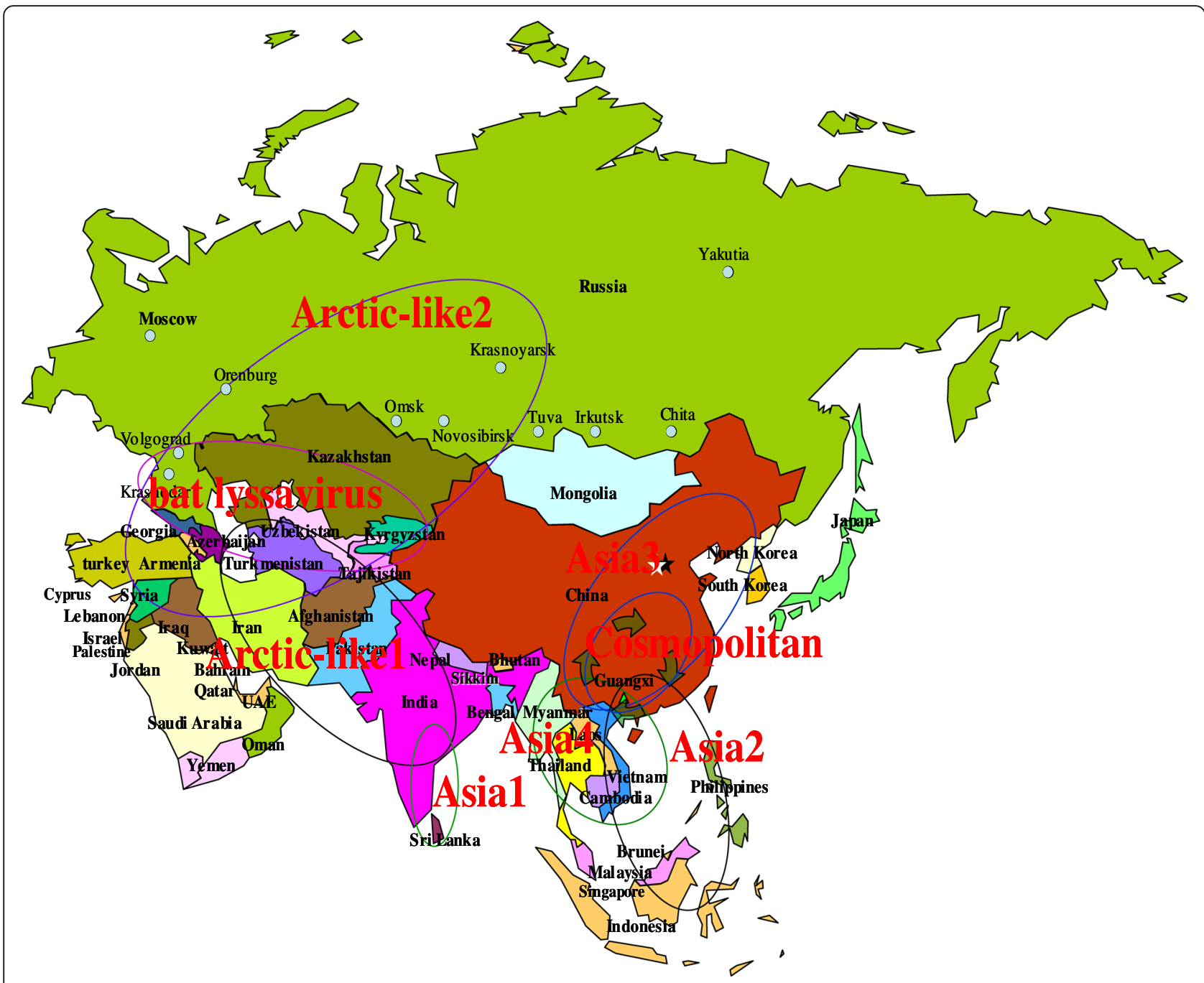

Fig. 2 Distribution of RABV isolates from Asia

Compared with the other genes, $\mathrm{P}$ gene also included several sporadic variations in group I and II, resulting in the variation rate of the $\mathrm{P}$ gene being higher than the other genes. In group I, four isolates (GXS822010, GXBS13201, GXNNSL and GXLB19) had H57F sporadic variation and three isolates (GXNND, GXLB and GXHX82) had M69 V variation. In group II, there were eight sporadic variations. Of which, five isolates (GXBS89201, GXBA09201, GXLQ2010, GXLB2010 and GXBN2011) had three sporadic variations (H57F, M69G and A70T); four isolates (GXNN2, GXLCC, GXPL, and GXYZD) had four sporadic variations (G61R/K, K62 N, T157I and A170V); four isolates (GX074, GXPX, GXPXD and GXLA11) had one sporadic variation (at N292S); GXHXN isolates had three sporadic variations (H57P, M69G and A70T; Additional file 5: Table S5).

\section{$M$ amino acid variations}

For the $M$ protein, there were nine substitutions (L26P, S46G, G58E, K77R, S104A, F120 L, I158S, K160R and P175S) common to the three groups I, II and III, one specific substitution I168V in group I, and four specific substitutions (Q17H, S20F, P21S and V22A) in group II. And a functional motif PxSAP [29] mapped at 21-25aa included P21S and V22A variations; its P21S change indicated that the PxSAP motif was abolished in the group II. Another motif PPxY at 35-38aa, relating to viral budding [29], was highly conserved (Additional file 6: Table S6). In addition, the amino acid Y138 that was highly conserved in virulent or avirulent RABV strains was mapped as a functional residue corresponding to viral replication (data not shown).

\section{$L^{1-680}$ and the $L^{\text {pam }}$ amino acid variations}

Alignment of the 226 amino acids of the $\mathrm{L}^{1-680}$ fragment revealed four substitutions (R115K, I117M, A168S, and 


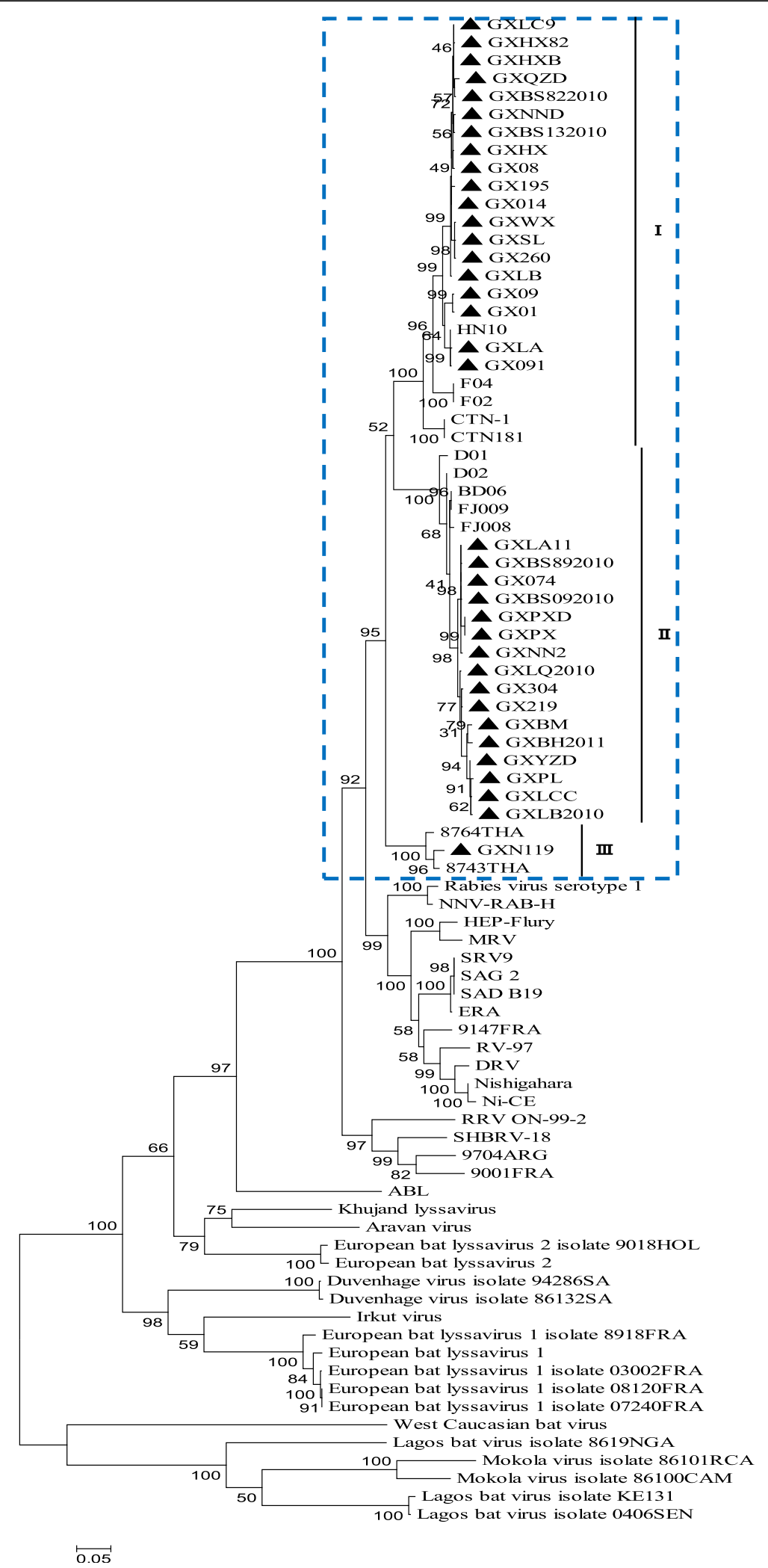

Fig. 3 Phylogenetic tree based on nucleotide sequences of the RABV P gene 


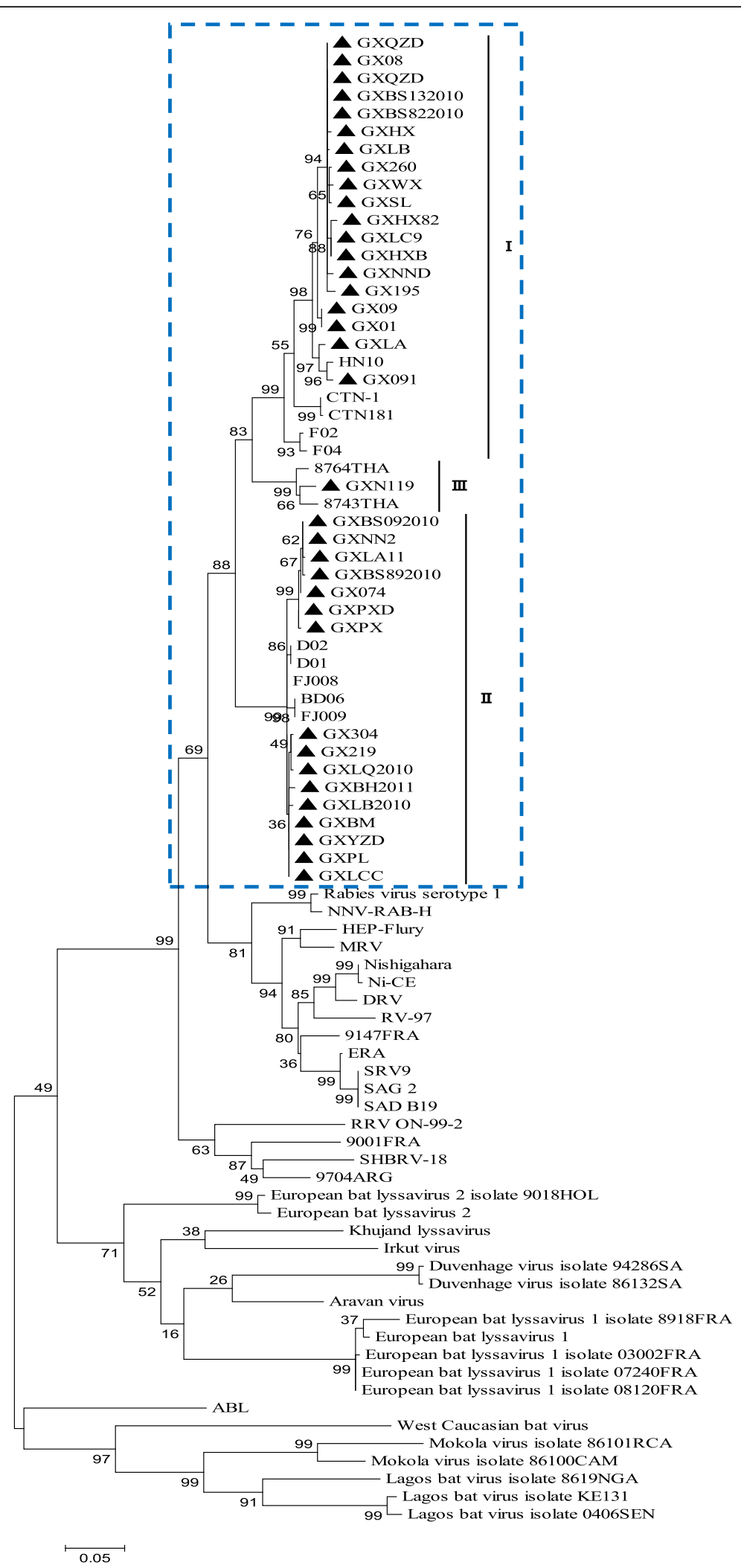

Fig. 4 Phylogenetic tree based on nucleotide sequences of the RABV M gene 


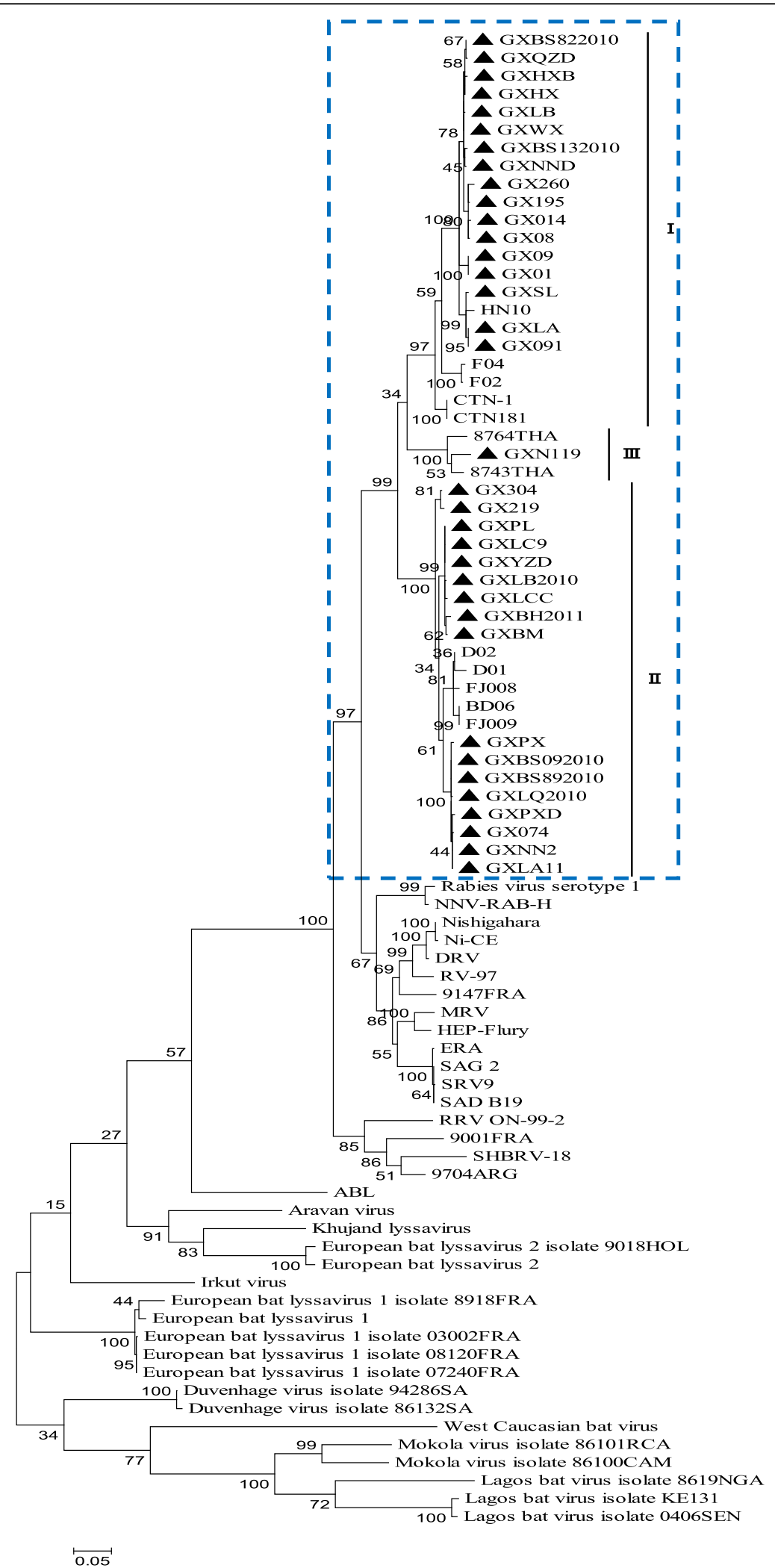

Fig. 5 Phylogenetic tree based on nucleotide sequences of the RABV $3^{\prime}$ terminal in the $L$ gene $\left(L^{1-680}\right)$ 


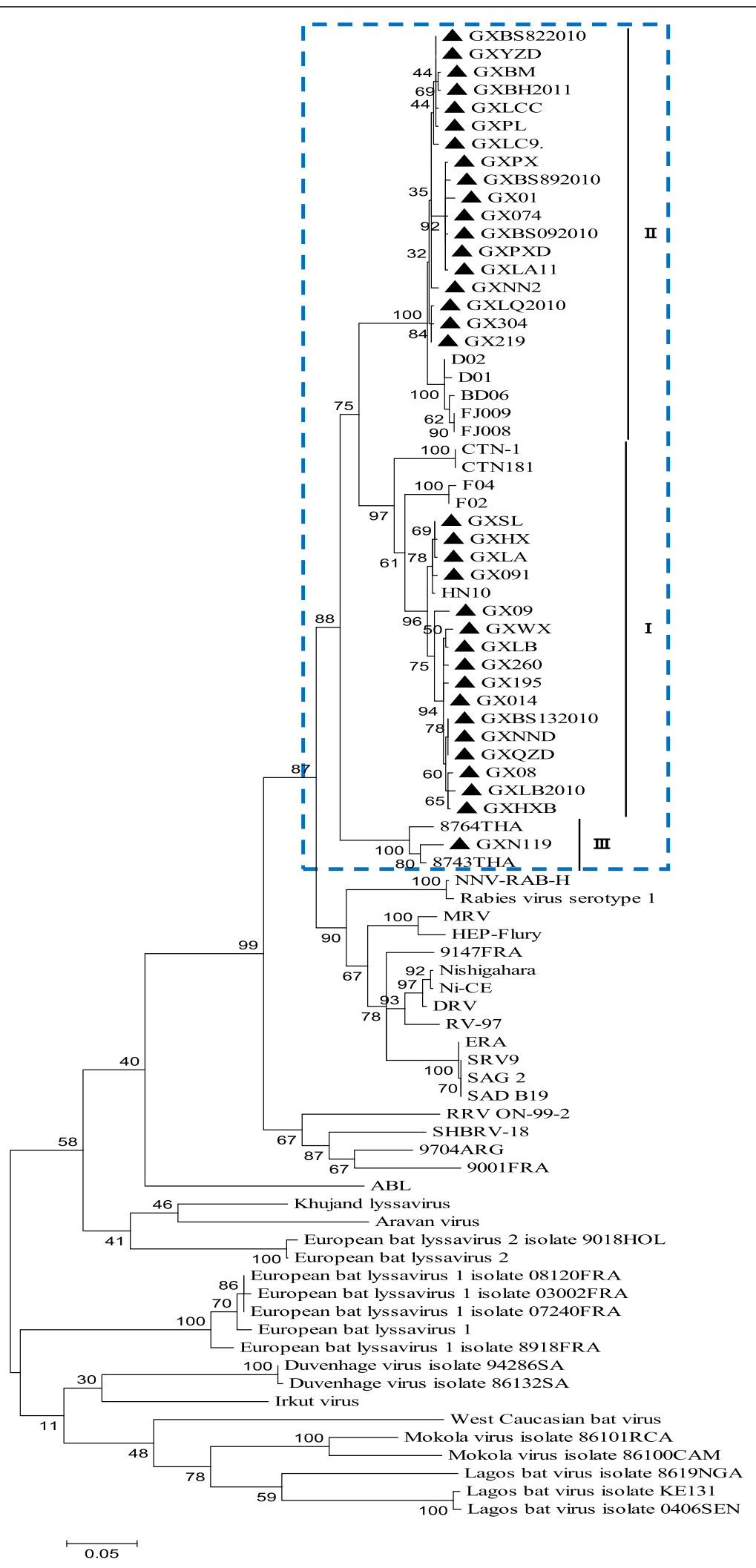

Fig. 6 Phylogenetic tree based on nucleotide sequences of the RABV polymerase activity module in the $L$ gene $\left(L^{\text {pam }}\right)$ 


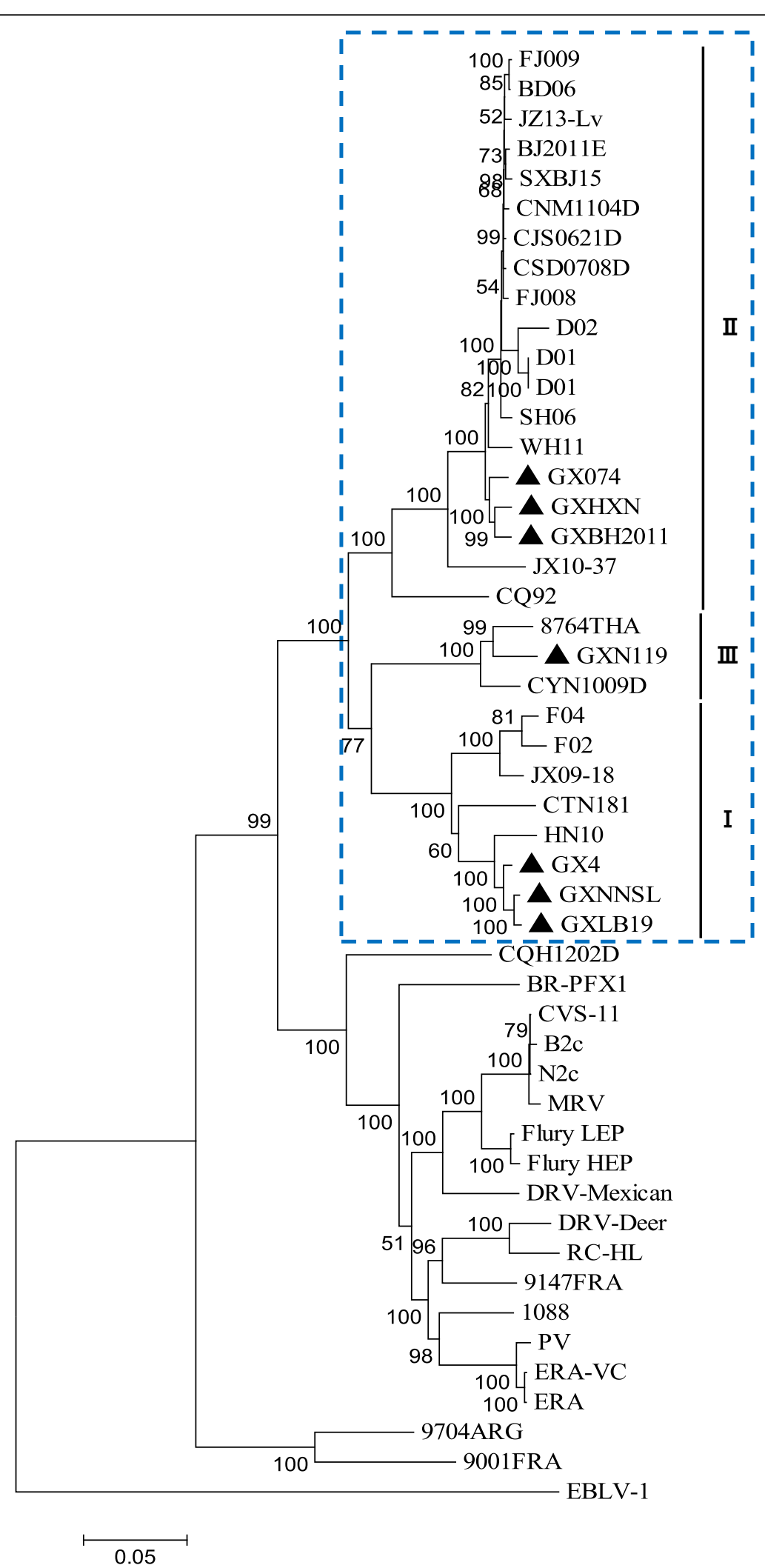

Fig. 7 Phylogenetic tree based on RABV whole genome nucleotide sequences 
Table 1 Comparison of genetic patterns based on different genes of rabies virus from Guangxi.

\begin{tabular}{cccc}
\hline Virus gene & & Group pattern & \\
& & & \\
\hline Virus genome & II & III & I \\
N & II & I & III \\
G & II & I & III \\
L $^{\text {pam }}$ & II & I & III \\
P & I & II & III \\
M & I & III & II \\
$\mathrm{L}^{1-680}$ & I & III & II \\
\hline
\end{tabular}

Shading illustrates which groups were most closely related.

I207V) that were specific to group I, one substitution (T64A) that was specific to group II, and five substitutions (L76F, L88 V, T118A, V157I, and D190E) that were specific to group III. The R48K substitution was common to groups I and II, while V83 L was common to groups II and III. Notably seven substitutions (L2I, L17S, D19A, F73Y, R74K, L136C, and N161 K) were common to all three groups (Table 2).

Among the 200 amino acids of the $L^{\text {pam }}$ fragment we found one substitution, S162A, specific to group I and another, I51V, specific to group II (Table 2).

These data are summarized in Table 2 and Additional file 4: Table S4, Additional file 5: Table S5, Additional file 6: Table S6, which demonstrate that amino acid variations differ across the three groups and serve as viral genetic markers in each of the proteins of wild RABV isolates from Guangxi.

\section{Whole genome amino acid variation}

The sizes of the individual structural genes, functional motifs and important functional sites of the five RABV isolates for which whole genome sequencing was performed were mostly consistent, with few sites differing. Relative to the coding regions, the non-coding regions were more variable. The full genome of five RABV isolates contained 11,921-11,924 nt in length: $11921 \mathrm{nt} /$ GXLB19; 11,922 nt/GXNNSL and GX4 isolate (from Guangxi downloaded from GenBank); and 11,924 nt/ GXBH2011, GXN119, GX074. The P-M non-coding regions were 86-87 nt in length, while the 5' UTR regions were $129-131 \mathrm{nt}$ in length (Table 3 ).

The nAchR-binding region located at 189-214aa of G protein [30] had one common variation E205K in the five isolates. Transcription initiation (AACA) was extremely conserved. In the G-L non-coding region, there are two transcription termination poly: $\mathrm{A}_{7}$ (TTP) motifs located downstream of the $G$ protein stop codon. According to the whole genome sequences of the five RABV isolates from Guangxi, the 1st TTP motif (70-77 nt) had 3-5 nt changed, while the second TTP motif located 470-477 nt was conserved and observed in all five isolates (Table 4).

\section{Discussion}

Rabies is a severe epidemic in Guangxi, China, with hundreds of deaths occurring each year [22], and globally the number of rabies cases in China is second only to India [31]. In the past six decades, rabies has emerged three times in Guangxi, which has the largest number of rabies cases in China. The 1st outbreak of rabies was from 1968 to 1976, with the peak of human rabies cases at 560 in 1972. The 2nd time occurred in 1978, reaching a peak of 879 human rabies cases in 1981 , and then gradually decreasing to just 24 cases in 1995. However, in the 3rd time, the number of human rabies cases increased from 50 in 1996, rose steeply to 203 in 2003, and reached a peak of 602 in 2004 [22].

The domestic dog is the principal vector for rabies, and $95 \%$ of human cases are associated with transmission from dogs. Our research group began surveillance of the RABV-carriage rate of at least 500 clinically healthy dogs from rural areas of Guangxi from 1999, and isolated RABV from RABV-positive cases. Of these isolates, several from rabid and normal dogs taken at different times showed similar pathogenicity in mice, indicating that the RABV from Guangxi has stable virulence [22]. Nevertheless, following an increase in dog vaccination in rural areas, the RABV-carriage rate in dogs appears to be gradually decreasing (data not shown). Between 2013 and 2016, we did not obtain any positive samples even though at least 500 samples from different areas in Guangxi were tested each year. Therefore, the data shown in this study consists of RABV isolates collected up until 2012. After reviewing a molecular epidemiological study conducted in Guangxi [15], we decided to further examine the genetic properties of these RABV isolates.

Generally, similar phylogenetic trees imply similar evolutionary paths [32-34]. In the phylogenetic analysis of $\mathrm{Wu}$ et al., trees constructed with the N, P, M, G, and L 


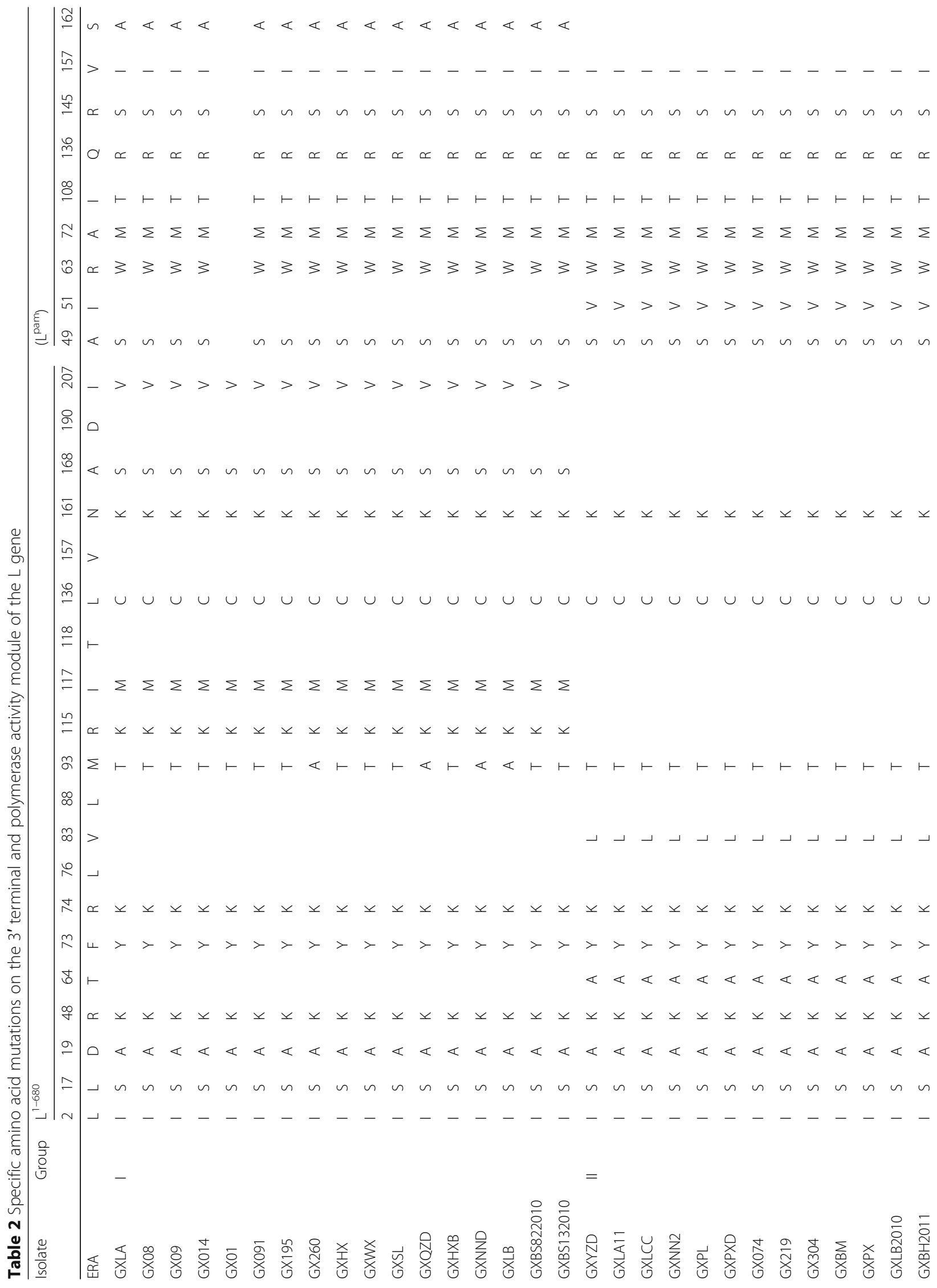




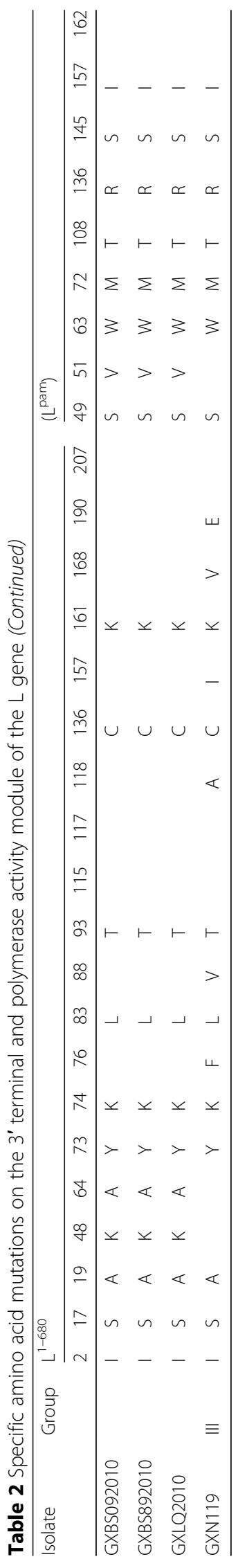


Table 3 Non-coding regions, coding regions and genome sizes of rabies virus isolates. Numbers represent sizes in base pairs

\begin{tabular}{lllllll}
\hline & GXLB19 & GXNNSL & GXBH2011 & GXN119 & GX074 & GX4 \\
\hline $3^{\prime}$ UTR & 70 & 70 & 70 & 70 & 70 & 70 \\
N & 1353 & 1353 & 1353 & 1353 & 1353 & 1353 \\
N-P & 91 & 91 & 91 & 91 & 91 & 91 \\
P & 894 & 894 & 894 & 894 & 894 & 894 \\
P-M & 86 & 86 & 87 & 87 & 87 & 86 \\
M & 609 & 609 & 609 & 609 & 609 & 609 \\
M-G & 211 & 211 & 211 & 211 & 211 & 211 \\
G & 1575 & 1575 & 1575 & 1575 & 1575 & 1575 \\
G-L & 516 & 516 & 516 & 516 & 516 & 516 \\
L & 6387 & 6387 & 6387 & 6387 & 6387 & 6387 \\
5' UTR & 129 & 130 & 131 & 131 & 131 & 130 \\
genome & 11,921 & 11,922 & 11,924 & 11,924 & 11,924 & 11,922 \\
\hline
\end{tabular}

genes were found to have similar topologies [8]. In this study, the phylogenetic trees constructed from the complete $\mathrm{N}, \mathrm{P}$, and $\mathrm{M}$ genes as well as the $\mathrm{L}^{1-680}$ and $L^{\text {pam }}$ fragments exhibited different topologies with strong bootstrap values as well as G gene (Table 1) [22], although the Guangxi RABV isolates of three groups were closely related (Figs. 1, 3, 4, 5, 6, and 7). The possible reason might be a difference of variation rate (varied nucleotides/total nucleotides of each gene) in each gene $[35,36]$. The comprehensive datasets of the $\mathrm{N}, \mathrm{P}$, $\mathrm{M}, \mathrm{L}^{1-680}$, and $\mathrm{L}^{\text {pam }}$ genes, widely distributed across different provinces of China, corroborated the assumption that the Guangxi RABV genes were likely undergoing co-evolution.

It is worth mentioning that although phylogenetic trees of the $N, P$, and $M$ genes and the $L^{1-680}$ and $L^{\text {pam }}$ fragments consistently had three groups, branching of the three viral groups actually revealed four different patterns. The tree generated from the N, G gene and $\mathrm{L}^{\mathrm{pam}}$ has a branching pattern in which groups II (Asia 3) and I (Asia2) are linked with group III (Asia4) lying on a separate branch; the trees generated from $\mathrm{P}$ gene had groups I and II clustered most closely with group III forming an outlying branch; trees generated from the $M$ and $\mathrm{L}^{1-680}$ genes and whole genome sequences had groups I and III most closely related, with group II as an outlying branch. This finding indicates that the rate of evolution might vary depending on the RABV gene examined (Table 1).

Based on the phylogenetic analysis and amino acid variation, the RABV isolates from Guangxi were divided into two main groups (I and II) and a minor group (III). However, the phylogenetic trees constructed from the complete $\mathrm{N}, \mathrm{P}$ and $\mathrm{M}$ genes as well as the $\mathrm{L}^{1-680}$ and $\mathrm{L}^{\text {pam }}$ fragments exhibited different topologies with strong bootstrap values as well as $\mathrm{G}$ gene. In fact, most of the isolates from the south China including Hunan, Guizhou, Guangdong, Fujian, Jiangsu, Anhui and Henan provinces belong to two main groups, the same as those isolates from Guangxi. Nevertheless, some isolates from Hunan, Guizhou, Jiangsu, Anhui, and Henan provinces are classified into the group Cosmopolitan (Fig. 1).

On the basis of differences identified by the phylogenetic analysis of nucleotide sequences, the downstream significance of these variations at the protein level was explored. Protein alignment revealed several specific amino acid residue mutations in each protein, which coincided with the phylogenetic analysis and grouping of isolates from Guangxi. Construction of phylogenetic trees and comparison of amino acids of each protein revealed an overall picture of significant genetic diversity for the isolates from Guangxi.

Table 4 Functional domain of rabies virus

\begin{tabular}{lccc}
\hline Virus & nAchR-binding domain (189-214 aa) of G gene & \multicolumn{2}{c}{ TTP motif of G-L noncoding region } \\
\cline { 2 - 4 } & & TTP1 & TTP2 \\
\hline ERA & CDIFTNSRGKRASKGSETCGFVDERG & GAAAAAAA & GAAAAAAA \\
GXLB19 & $-------------\mathrm{K}-------$ & - GGG-C $-\mathrm{T}$ & -------- \\
GXNNSL & $--------------\mathrm{K}--------$ & $-\mathrm{GGG}-\mathrm{C}-\mathrm{T}$ & -------- \\
GXBH2011 & $\mathrm{R}------------$ GK-------- & $-\mathrm{GG}--\mathrm{C}-\mathrm{T}$ & -------- \\
GXHXN & $--------------\mathrm{K}--------$ & $-\mathrm{GG}--\mathrm{C}-\mathrm{T}$ & -------- \\
GXN119 & $--------------\mathrm{K}--------$ & $-\mathrm{GGG}-\mathrm{C}-\mathrm{T}$ & -------- \\
\hline
\end{tabular}


In this study, we present the sequences of the entire $\mathrm{N}, \mathrm{P}$, and $\mathrm{M}$ genes and the $\mathrm{L}^{1-680}$ and $\mathrm{L}^{\mathrm{pam}}$ fragments of the $\mathrm{L}$ gene from $42 \mathrm{RABV}$ isolates from Guangxi. We previously also sequenced the full length $G$ gene for which we performed phylogenetic analysis [22]. The final results revealed that Maximum likelihood (ML) of the $\mathrm{N}$ gene sequences generated a tree with a similar overall structure to that obtained with the $G$ gene and $L^{\text {pam }}$ sequences [22], while different to that obtained using $\mathrm{P}$, $M$ gene and $\mathrm{L}^{1-680}$. In addition, the deduced amino acid sequences of the $\mathrm{N}, \mathrm{P}$, and $\mathrm{M}$ proteins and $\mathrm{L}^{1-680}$ and $\mathrm{L}^{\mathrm{pam}}$ for all 42 isolates from Guangxi were aligned and compared to other terrestrial strains. Variations in the $\mathrm{N}$ protein demonstrated different patterns to those obtained for the $\mathrm{P}$ and $\mathrm{M}$ proteins, and for the $\mathrm{L}^{1-680}$ and $\mathrm{L}^{\mathrm{pam}}$ fragments of the $\mathrm{L}$ protein, as well as for the $\mathrm{G}$ protein [22]. RNA variation in RABV isolates from Guangxi revealed a significant genetic diversity with differences observed from other geographical regions, and there are strong geographical associations among RABV isolates including the three groups in Guangxi.

Although live attenuated oral rabies vaccines could revert to virulent strains and have residual pathogenicity in certain rodents, they have been shown to be safe in foxes, dogs and skunks [37, 38]. Intensive molecular investigation of SAD B19 strain passaged several times in mice has demonstrated their sequence conservation and genetic stability in vivo [39]. However, there is always a risk that vaccine strains could revert to a fully pathogenic form, and thus, all RABV isolates collected from the field should be sequenced and subjected to phylogenetic analysis. We found that the attenuated vaccine ERA strain used across Guangxi was genetically distributed in a different group compared with the Guangxi RABV isolates (Figs. 1, 3, 4, 5, 6 and 7).

Here, we performed a detailed genetic analysis of RABV isolates from Guangxi. These data provide rich genetic information on nucleotide and amino acid variation patterns in RABV proteins and reveal genetic diversity in the RABV epidemic in Guangxi.

\section{Additional files}

Additional file 1: Table S1. Reference sequences of Lyssaviruses used in the present study. (DOC $282 \mathrm{~kb}$ )

Additional file 2: Table S2. Primers used in this study. (DOC 184 kb)

Additional file 3: Table S3. Origin of rabies virus isolates from Guangxi used in this study. (DOC $288 \mathrm{~kb}$ )

Additional file 4: Table S4. Specific amino acids mutations in the nucleoprotein (N) of rabies virus isolates from Guangxi. (DOCX $19 \mathrm{~kb}$ )

Additional file 5: Table S5. Specific mutational amino acid on phosphoprotein (P) protein of rabies virus isolates from Guangxi. (DOCX $23 \mathrm{~kb}$ )

Additional file 6: Table S6. Specific mutational amino acid on matrix protein of rabies virus isolates from Guangxi. (DOCX $22 \mathrm{~kb}$ )

\section{Abbreviations}

G: Glycoprotein; $L^{1-680}$ : 3' terminal 1-680 amino aicd in $L$ gene;

$L^{\text {pam: }}$ Polymerase activity module in $L$ gene; M: Matrix protein;

N: Nucleoprotein; P: Phosphoprotein; RABV: Rabies virus

\section{Acknowledgements}

The authors wish to thank the study participants for their contribution to the research, as well as current and past investigation and staff.

\section{Funding}

The study was supported by the National Natural Science Foundation of China (31570147), and the Fund Program of the Director of the Key Laboratory of the Ministry of Education for Microbial and Plant Genetic Engineering, Guangxi University. The funding body was solely involved in funding and had no role in the design of the study, the collection, analysis, and interpretation of the data, nor in writing the manuscript.

\section{Availability of data and materials}

All relevant data are within this paper. Original data are available from the corresponding author (tingrongluo@gxu.edu.cn) on reasonable request.

\section{Authors' contributions}

XKW collected and analyzed the data, and led the preparation of the manuscript. XXH, YP, HBT, CL, YZZ, XNL, JJL contributed to the project by collecting and analyzing the data. TRL supervised the project and provided substantial contributions to the analysis and interpretation of the data, and the preparation of the manuscript. All authors approved the final manuscript.

\section{Ethics approval}

All animal experiments described in this paper were conducted according to the National Guideline on the Humane Treatment of Laboratory Animals Welfare (MOST of People's Republic of China, 2006, China) and approved by the Animal Welfare and the Animal Experimental Ethical Committee (Guangxi University, No. Xidakezi2000138). All husbandry procedures were conducted in compliance with the Animal Welfare Act and the Guide for the Care and Use of Laboratory Animals.

\section{Competing interests}

All authors declare that they have no competing interests.

\section{Publisher's Note}

Springer Nature remains neutral with regard to jurisdictional claims in published maps and institutional affiliations.

Received: 18 January 2018 Accepted: 1 June 2018

Published online: 18 June 2018

References

1. Bourhy H, Kissi B, Tordo N. Taxonomy and evolutionary studies on lyssaviruses with special reference to Africa. Onderstepoort J Vet Res. 1993; 60(4):277-82.

2. Kissi B, Tordo N, Bourhy H. Genetic polymorphism in the rabies virus. nucleoprotein gene. Virology. 1995;209(2):526-37.

3. He W, Zhang H, Zhang Y, Wang R, Lu S, Ji Y, Liu C, Yuan P, Su S. Codon usage bias in the N gene of rabies virus. Infect Genet Evol. 2017;54:458-65.

4. Zhang J, Zhang Z, Deng Y, Wu S, Wang W, Yan Y. Incidence of human rabies and characterization of rabies virus nucleoprotein gene in dogs in Fujian Province, Southeast China, 2002-2012. BMC Infect Dis. 2017;17(1):599.

5. Badrane H, Bahloul C, Perrin P, Tordo N. Evidence of two lyssavirus phylogroups with distinct pathogenicity and immunogenicity. J Virol. 2001; 75(7):3268-76.

6. Kuzmin I, Orciari L, Arai Y, Smith J, Hanlon C, Kameoka Y, Rupprecht C. Bat lyssaviruses (Aravan and Khujand) from Central Asia: phylogenetic relationships according to N, P and G gene sequences. Virus Res. 2003; 97(2):65-79

7. Kuzmin I, Hughes G, Botvinkin A, Orciari L, Rupprecht C. Phylogenetic relationships of Irkut and west Caucasian bat viruses within the lyssavirus genus and suggested quantitative criteria based on the $\mathrm{N}$ gene sequence for lyssavirus genotype definition. Virus Res. 2005;111(1):28-43.

8. Wu X, Franka R, Velasco-Villa A, Rupprecht C. Are all lyssavirus genes equal for phylogenetic analyses? Virus Res. 2007;129(2):91-103. 
9. Delmas O, Holmes E, Talbi C, Larrous F, Dacheux L, Bouchier C, Bourhy H. Genomic diversity and evolution of the lyssaviruses. PLoS One. 2008; 3(4):e2057.

10. Zhang Y, Xiong C, Zou Y, Wang D, Jiang R, Xiao Q, Hao Z, Zhang L, Yu Y, Fu Z. Molecular characterization of rabies virus isolates in China during 2004. Virus Res. 2006;121(2):179-88.

11. Zhang Y, Xiong C, Lin X, Zhou D, Jiang R, Xiao Q, Xie X, Yu X, Tan Y, Li M, et al. Genetic diversity of Chinese rabies viruses: evidence for the presence of two distinct clades in China. Infect Genet Evol. 2009;9(1):87-96.

12. Tao X, Tang Q, Li H, Mo Z, Zhang H, Wang D, Zhang Q, Song M, VelascoVilla A, Wu X, et al. Molecular epidemiology of rabies in southern People's Republic of China. Emerging Infect Dis. 2009;15(8):1192-8.

13. Ming P, Yan J, Rayner S, Meng S, Xu G, Tang Q, Wu J, Luo J, Yang X. A history estimate and evolutionary analysis of rabies virus variants in China. J Gen Virol. 2010;91(Pt 3):759-64.

14. Gong W, Jiang Y, Za Y, Zeng Z, Shao M, Fan J, Sun Y, Xiong Z, Yu X, Tu C. Temporal and spatial dynamics of rabies viruses in China and Southeast Asia. Virus Res. 2010;150(1-2):111-8

15. Liu Q, Xiong Y, Luo T, Wei Y, Nan S, Liu F, Pan Y, Feng L, Zhu W, Liu K, et al. Molecular epidemiology of rabies in Guangxi Province, south of China. J Clin Virol. 2007;39(4):295-303

16. Thompson J, Gibson T, Higgins D. Multiple sequence alignment using ClustalW and ClustalX. Curr Protoc Bioinformatics. 2002;Chapter 2(Unit 2):3.

17. Tamura K, Dudley J, Nei M, Kumar S. MEGA4: molecular evolutionary genetics analysis (MEGA) software version 4.0. Mol Biol Evol. 2007;24(8): 1596-9.

18. Su S, Wong G, Shi W, Liu J, Lai A, Zhou J, Liu W, Bi Y, Gao G. Epidemiology, genetic recombination, and pathogenesis of coronaviruses. Trends Microbiol. 2016;24(6):490-502

19. Lang SL, Tao XY, Guo ZY, Tang Q, Li H, Yin CP, Li Y, Liang GD. Molecular characterization of viral $\mathrm{G}$ gene in emerging and re-emerging areas of rabies in China, 2007 to 2011. Virol Sin. 2012;27(3):194-203.

20. Tao XY, Tang Q, Rayner S, Guo ZY, Li H, Lang SL, Yin CP, Han N, Fang W, Adams J, et al. Molecular phylodynamic analysis indicates lineage displacement occurred in Chinese rabies epidemics between 1949 to 2010. PLoS Negl Trop Dis. 2013;7(7):e2294

21. Yu F, Zhang G, Zhong X, Han N, Song Y, Zhao L, Cui M, Rayner S, Fu ZF. Comparison of complete genome sequences of dog rabies viruses isolated from China and Mexico reveals key amino acid changes that may be associated with virus replication and virulence. Arch Virol. 2014; 159(7):1593-601.

22. Tang H, Pan Y, Wei X, Lu Z, Lu W, Yang J, He X, Xie L, Zeng L, Zheng L, et al. Re-emergence of rabies in the Guangxi province of southern China. PLoS Negl Trop Dis. 2014;8(10):e3114.

23. Kouznetzoff A, Buckle M, Tordo N. Identification of a region of the rabies virus $\mathrm{N}$ protein involved in direct binding to the viral RNA. The Journal of general virology. 1998;79(Pt 5):1005-13

24. Dietzschold B, Wunner WH, Wiktor TJ, Lopes AD, Lafon M, Smith CL, Koprowski $\mathrm{H}$. Characterization of an antigenic determinant of the glycoprotein that correlates with pathogenicity of rabies virus. Proc Natl Acad Sci U S A. 1983:80(1):70-4

25. Chenik M, Schnell M, Conzelmann KK, Blondel D. Mapping the interacting domains between the rabies virus polymerase and phosphoprotein. J Virol. 1998;72(3):1925-30.

26. Lo KW, Naisbitt S, Fan JS, Sheng M, Zhang M. The 8-kDa dynein light chain binds to its targets via a conserved (K/R)XTQT motif. J Biol Chem. 2001; 276(17):14059-66.

27. Jacob Y, Real E, Tordo N. Functional interaction map of lyssavirus phosphoprotein: identification of the minimal transcription domains. J Virol. 2001;75(20):9613-22.

28. Toriumi $\mathrm{H}$, Kawai $\mathrm{A}$. Association of rabies virus nominal phosphoprotein (P) with viral nucleocapsid (NC) is enhanced by phosphorylation of the viral nucleoprotein (N). Microbiol Immunol. 2004;48(5):399-409.

29. Jayakar HR, Murti KG, Whitt MA. Mutations in the PPPY motif of vesicular stomatitis virus matrix protein reduce virus budding by inhibiting a late step in Virion release. J Virol. 2000;74(21):9818-27.

30. Lentz T, Wilson P, Hawrot E, Speicher D. Amino acid sequence similarity between rabies virus glycoprotein and snake venom curaremimetic neurotoxins. Science. 1984:226(4676):847-8.
31. Tan J, Wang R, Ji S, Su S, Zhou J. One health strategies for rabies control in rural areas of China. Lancet Infect Dis. 2017;17(4):365-7.

32. Song M, Tang Q, Wang D, Mo Z, Guo S, Li H, Tao X, Rupprecht C, Feng Z, Liang $G$. Epidemiological investigations of human rabies in China. BMC Infect Dis. 2009;9:210.

33. Hafner M, Nadler S. Phylogenetic trees support the coevolution of parasites and their hosts. Nature. 1988;332(6161):258-9.

34. Korn E. Coevolution of head, neck, and tail domains of myosin heavy chains. Proc Natl Acad Sci U S A. 2000;97(23):12559-64.

35. Bourhy H, Reynes J, Dunham E, Dacheux L, Larrous F, Huong V, Xu G, Yan J, Miranda M, Holmes E. The origin and phylogeography of dog rabies virus. J Gen Virol. 2008;89(Pt 11):2673-81.

36. Talbi C, Holmes $E$, de Benedictis P, Faye $O$, Nakouné E, Gamatié D, Diarra A, Elmamy B, Sow A, Adjogoua E, et al. Evolutionary history and dynamics of dog rabies virus in western and Central Africa. J Gen Virol. 2009;90(Pt 4):783-91.

37. Vos A. Oral vaccination against rabies and the behavioural ecology of the red fox (Vulpes vulpes). J Vet Med B Infect Dis Vet Public Health. 2003; 50(10):477-83.

38. Vos A, Pommerening E, Neubert L, Kachel S, Neubert A. Safety studies of the oral rabies vaccine SAD B19 in striped skunk (Mephitis mephitis). J Wildl Dis. 2002;38(2):428-31.

39. Beckert A, Geue L, Vos A, Neubert A, Freuling C, Müller T. Genetic stability (in vivo) of the attenuated oral rabies virus vaccine SAD B19. Microbiol Immunol. 2009;53(1):16-21.

\section{Ready to submit your research? Choose BMC and benefit from:}

- fast, convenient online submission

- thorough peer review by experienced researchers in your field

- rapid publication on acceptance

- support for research data, including large and complex data types

- gold Open Access which fosters wider collaboration and increased citations

- maximum visibility for your research: over $100 \mathrm{M}$ website views per year

At BMC, research is always in progress.

Learn more biomedcentral.com/submissions 